\title{
Association between drinking patterns and cardiovascular risk: a population-based study in the Southern Cone of Latin America
}

\section{Pablo Elías Gulayin ${ }^{1,2}$, Vilma Irazola ${ }^{1}$, Laura Gutierrez ${ }^{1}$, Natalia Elorriaga ${ }^{1}$, Fernando Lanas ${ }^{3}$, Nora Mores ${ }^{4}$, Jaqueline Ponzo ${ }^{5}$, Matías Calandrelli ${ }^{6}$, Rosana Poggio ${ }^{1,7}$, Adolfo Rubinstein ${ }^{8}$, Ariel Bardach ${ }^{1,7}$}

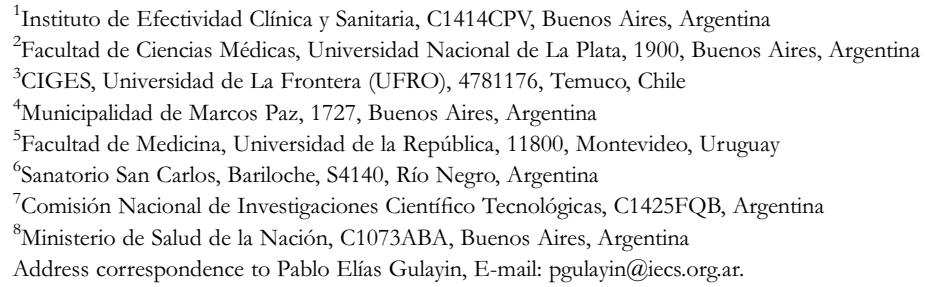

\begin{abstract}
Background Using data from general adult population, this study aims to describe epidemiology of alcohol consumption patterns and their association with cardiovascular risk.

Methods CESCASI is a population-based study from four mid-sized cities in Argentina, Chile and Uruguay. Associations between diabetes, hypertension, dyslipidemia, cardiovascular disease (CVD) risk and history of CVD and drinking patterns were assessed using crude prevalence odds ratios (ORs) and adjusted OR.

Results A total of $37.2 \%$ of the studied population never drank and $18.3 \%$ reported to be former drinkers. Among current drinkers, moderate drinking was the most frequent pattern (24.2\%). For women with light and moderate consumption, the odds of having $>20 \%$ CVD risk was $\sim 40 \%$ lower than that of never drinkers. The odds of having a history of CVD was $50 \%$ lower in those with moderate consumption. For men with heavy consumption, the odds of having $>20 \%$ CVD risk was about twice as high as for never drinkers.

Conclusions A harmful association was observed between heavy drinking and having >20\% CVD risk for men. However, for women, an apparently protective association was observed between light and moderate drinking and having $>20 \%$ CVD risk and between moderate drinking and having a history of CVD.
\end{abstract}

Keywords alcohol consumption, circulatory disease, epidemiology

\section{Introduction}

In 2012 , it was estimated that $5.9 \%$ of total deaths and a burden of 5.1 years of life adjusted for disability (DALYs) were attributed to alcohol consumption worldwide. ${ }^{1}$ The 2016 edition of Institute for Health Metrics and Evaluation (IHME) global burden of disease study (GBD), estimated that a significant toll of $\sim 335000$ deaths globally were caused by cirrhosis and other chronic liver diseases due to alcohol use and $\sim 174000$ deaths were from alcohol use disorders. ${ }^{2}$

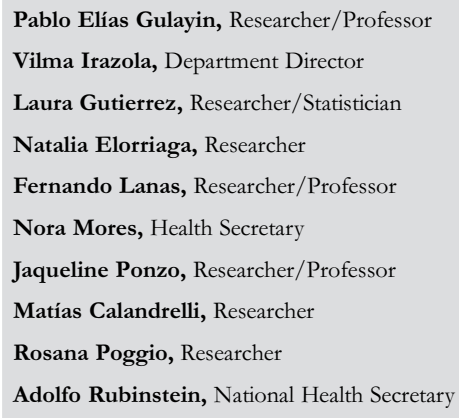

Ariel Bardach, Researcher 
In Argentina, Chile and Uruguay alcohol per capita consumption is among the highest in Latin America. ${ }^{3}$ Only in Argentina there are 2.3 million new consumers yearly. ${ }^{4}$ High alcohol consumption has been clearly associated with accidents, different types of cancers, liver cirrhosis, hemorrhagic stroke, alcoholic cardiomyopathy and other conditions. ${ }^{5}$ However, moderate alcohol consumption has been suggested to be associated with protective effects for some conditions, depicting a possible J-shaped relationship for cardiovascular disease (CVD), ${ }^{6-11}$ diabetes mellitus and all-cause mortality. ${ }^{3,7}$ In fact, the effect of alcohol and CVD appears to be complex and mediated through various pathophysiological mechanisms. Although some studies state that light to moderate alcohol consumption could be associated with lower risk of coronary heart disease and total mortality ischemic heart disease, ${ }^{12,13}$ high alcohol consumption has also been related to hypertensive disease ${ }^{14}$ arrhythmias $^{15}$ and stroke. ${ }^{16}$

Moreover, quantification of effects on CVD is also complex. Our group estimated that the cardio-protective effect of regular and moderate alcohol drinking on CVD slightly outweighed the harmful impact of binge drinking on CVD in $2010 .{ }^{17}$ Drinking volume, frequency and patterns are important to establish risk, since binge drinking for example, has been shown to increase alcohol-attributable mortality. ${ }^{18-20}$

World Health Organization (WHO) published the Global Status Report on Alcohol with data from several countries in an effort to generate comparable data across different countries ${ }^{21}$; however, there is very little research on alcohol consumption and its deleterious effects from a public health perspective in the Southern Cone of Latin America. It is largely unknown what the drinking patterns are in this region, or the degree of exposure of the population to different volumes. National surveys in Argentina and Uruguay shed some light showing that half of the population reported having consumed alcohol in the last 30 days, being that prevalence higher in men than in women in both countries. $^{22,23}$ The objective of this article is to describe the epidemiology of alcohol consumption patterns and their association with cardiovascular risk the in the general adult population of four cities in the Southern Cone of Latin America.

\section{Methods}

\section{Study participants}

The CESCAS (Centro de Excelencia en Salud Cardiovascular para el Cono Sur) I study is a populationbased study with multistage probabilistic sampling in general population from four representative cities in the Southern Cone of Latin America, aimed to examine CVD and risk factors. CESCAS I design and sampling method have been published elsewhere. $^{24,25}$ Briefly, 7524 women and men, aged 35 to 74 years old, were recruited between February 2010 and December 2011 from population-representative samples of four small to mid-sized cities in the Southern Cone of Latin America: two in Argentina (Bariloche and Marcos Paz), one in Chile (Temuco) and one in Uruguay (Canelones-Barros Blancos). These study locations were selected based on population characteristics reflecting country averages. The overall response rate was $73.4 \%$, and these rates were similar in men and women and across different locations.

The study complies with the Declaration of Helsinki. The study protocol has been approved by Institutional Review Boards (IRBs) for all participating institutions in Argentina, Chile, Uruguay and USA. The written informed consent has been obtained from all study participants.

\section{Data collection}

Study data were collected at a home visit and a clinical visit by trained staff. During the home survey, information was obtained on demographic characteristics, including age, sex, education and occupation. Alcohol consumption data were collected through a structured questionnaire (appendix) based on the Hispanic Community Health Study/Study of Latinos cross-culturally adapted for use in Argentina, Chile and Uruguay. $^{24,26}$ Anthropometric measurements were obtained by trained and certified observers using standard protocols and techniques. Three blood pressure (BP) measurements were obtained with the participant in the seated position after 5 min of rest using a standard mercury or aneroid sphygmomanometer, and the mean of three readings was used for analysis. Body weight, height and waist circumference were measured twice during the examination and the average of two measurements was used in all analyses. Weight was measured in light indoor clothing without shoes in kilograms to one decimal place, using standing scales. Height was measured without shoes in centimeters to one decimal place using a wall-mounted stadiometer. Waist circumference was measured at $1 \mathrm{~cm}$ above the navel at minimal respiration, in centimeters to one decimal place.

Overnight fasting blood specimens were obtained for measurement of lipids, creatinine and glucose. The duration of fasting was verified before the blood specimen was obtained. Participants who had not fasted for at least 10 hours did not have their blood drawn. Blood glucose, total and High Density Lipoprotein (HDL) cholesterol and triglycerides were measured using standard methods. Concentration of Low Density Lipoprotein (LDL) cholesterol was calculated using the Friedewald equation for participants who had $<400 \mathrm{mg} / \mathrm{dl}$ triglycerides. $^{27}$ 


\section{Definitions}

Obesity was defined as body mass index (BMI) $\geq 30 \mathrm{~kg} / \mathrm{m}^{2}$ and overweight as BMI $\geq 25$ and $<30 \mathrm{~kg} / \mathrm{m}^{2}$. Hypertension was defined as mean systolic BP $\geq 140 \mathrm{~mm} \mathrm{Hg}$ and/or mean diastolic BP $\geq 90 \mathrm{~mm} \mathrm{Hg}$ and/or current use of antihypertensive medications. Dyslipidemia was defined as total cholesterol $\geq 240 \mathrm{mg} / \mathrm{dl}$ and/or LDL-cholesterol $\geq 160 \mathrm{mg} / \mathrm{dl}$ and/or HDL-cholesterol $<40 \mathrm{mg} / \mathrm{dl}$ and/or triglyceride $\geq 200 \mathrm{mg} / \mathrm{dl}$ and/or use of lipid-lowering medication. Diabetes was defined as fasting glucose $\geq 126 \mathrm{mg} / \mathrm{dl}$ and/or self-reported history of diabetes and/or current use of insulin or antidiabetic medications. History of CVD was registered by self-report and included self-reported history of heart attack, angina, revascularization, stroke/transient ischemic attack or heart failure. CVD risk was estimated using the Framingham Risk Score. ${ }^{28}$ Low CVD risk was defined as a $\leq 10 \% 10$-years risk, moderate as $10-20 \%$ and high risk as $>20 \% 10$-year-risk.

Patterns of alcohol consumption were classified according to Drinking Levels Defined as published by the National Institute of Alcohol Abuse and Alcoholism ${ }^{29}$ as the following mutually exclusive categories: never drinker, former drinkers (stopped drinking one or more years ago), moderate (up to seven drinks per week for women and up to 14 drinks per week for men); heavy drinker (eight or more drinks per week for women and 15 or more drinks per week for men) and binge drinker (any person that reported four drinks for women and five drinks for men, in $\sim 2$ hours more than once a month). Depending of average volume per day of drinking alcohol, participants were classified using the following classification published by $\mathrm{WHO}^{30}$ : abstainers (never and former drinkers), drinker I (females 0-19.99 gr pure alcohol daily, males 0-39.99 g pure alcohol), drinker II (females 20-39.99 g pure alcohol, males 40-59.99 g pure alcohol) and drinker III (females $\geq 40 \mathrm{~g}$ pure alcohol, males $\geq 60 \mathrm{~g}$ pure alcohol). Among drinkers, types of beverages were categorized as wine, beer and spirits based on consumption during last week. For drinkers who had not drunk during the previous week, the type of beverage was considered as undefined.

\section{Statistical analysis}

All estimates were weighed to represent the general adult population aged $35-74$ years in the study sites, according to the study sampling design. Estimates of prevalence were reported as proportions with $95 \%$ confidential intervals (CI). Standard errors were calculated by means of an appropriate technique for a complex survey design. ${ }^{24,31}$ To evaluate the validity of self-reported alcohol intake, one-way ANOVA with linear polynomial contrast was performed between
HDL-c levels and categories of average volume per day of drinking alcohol. Gender-stratified analyses were performed to explore behavioral differences between men and women. The association of diabetes, hypertension, dyslipidemia, cardiovascular risk and history of CVD with drinking patterns was assessed using crude prevalence odds ratios (ORs) and adjusted OR which were adjusted for age, education, city, hypertension, diabetes and current smoking. All data analyses were conducted using SAS 9.3 (SAS Institute, Cary $\mathrm{NC})$.

\section{Results}

\section{Demographic and risk factors}

Table 1 shows CESCAS participants baseline characteristics. In general, $29.7 \%$ of the CESCAS population reported to currently smoke cigarettes, $40.8 \%$ had hypertension, $12.4 \%$ had diabetes, $24.4 \%$ had hypercholesterolemia, $77 \%$ had overweight or obesity and 10\% reported history of CVD. Those characteristics were also stratified by sex, age groups and education level.

\section{Alcohol consumption epidemiology}

A positive linear association was observed between average volume per day alcohol consumption and HDL-c means levels: abstainers: $46.2 \mathrm{mg} \%$; DI: $46.9 \mathrm{mg} \%$; DII: $53.6 \mathrm{mg}^{\%}$ and DIII: $50.7 \mathrm{mg} \%$ (P: 0.0005).

Regarding patterns of drinking, the majority of the studied population reported not to be currently drinking $(37.2 \%$ never drank and $18.3 \%$ reported to be former drinker). Among current drinkers, moderate drinking was the most frequent pattern $(24.2 \%)$ followed by light (11.8\%), binge $(5.6 \%)$ and heavy drinking $(2.9 \%)$. Moderate alcohol consumption was the most frequent pattern of alcohol drinking among men, while among women never drinkers represented the highest prevalence across all age groups (Tables 2 and 3). Among men, the prevalence of heavy drinking was 3.9\% and the prevalence of binge drinking was $9.9 \%$. These prevalences were lower in women, $2 \%$ and $1.7 \%$, respectively.

Tables 2 and 3 also include analyses by average of pure alcohol consumed. Most of the current drinker population was type I drinker (42.6\%). This observation was consistent by sex and by the rest of the analyzed subgroups. Globally, the prevalence of type II and type III drinkers were $1.2 \%$ and $0.7 \%$ respectively. By sex, those levels of alcohol consumption were higher in men than in women.

The type of beverage most frequently reported by drinkers was wine $(51.7 \%)$ followed by beer (34.7\%) and spirits $(19.7 \%)$. Wine consumption prevalence was higher in older 
Table 1 General characteristics of the study population in the Southern Cone of Latin America ${ }^{a}$

\begin{tabular}{|c|c|c|c|c|c|c|c|}
\hline & $n$ & $\begin{array}{l}\text { Current cigarette } \\
\text { smoking }\end{array}$ & Hypertension & Diabetes & Dyslipidemia & $\begin{array}{l}\text { Overweight or } \\
\text { obesity }\end{array}$ & $\begin{array}{l}\text { History of } \\
\text { cardiovascular } \\
\text { disease }\end{array}$ \\
\hline Overall & 7524 & $29.7(28.4,31.0)$ & $40.8(39.4,42.1)$ & $12.4(11.5,13.3)$ & $58.4(57.0,59.8)$ & $77.0(75.8,78.1)$ & $10.0(9.2,10.7)$ \\
\hline \multicolumn{8}{|l|}{ Sex } \\
\hline Men & 3165 & $33.3(31.3,35.3)$ & $44.7(42.6,46.7)$ & $10.6(9.4,11.7)$ & $68.3(66.3,70.2)$ & $79.5(77.9,81.2)$ & $10.4(9.3,11.5)$ \\
\hline Women & 4359 & $26.5(24.8,28.3)$ & $37.3(35.5,39.0)$ & $14.0(12.8,15.3)$ & $49.6(47.7,51.5)$ & $74.6(73.0,76.3)$ & $9.6(8.5,10.6)$ \\
\hline \multicolumn{8}{|l|}{ Age groups (years) } \\
\hline $35-44$ & 1716 & $33.9(31.2,36.5)$ & $22.5(20.2,24.8)$ & $6.1(4.7,7.4)$ & $52.6(49.8,55.4)$ & $73.6(71.3,76.0)$ & $5.2(4.0,6.4)$ \\
\hline $45-54$ & 2072 & $35.8(33.4,38.1)$ & $38.8(36.4,41.2)$ & $11.1(9.5,12.7)$ & $59.6(57.1,62.0)$ & $77.5(75.4,79.5)$ & $8.1(6.8,9.4)$ \\
\hline $55-64$ & 2114 & $24.2(22.2,26.3)$ & $57.2(54.8,59.6)$ & $18.4(16.5,20.3)$ & $64.4(62.0,66.7)$ & $80.5(78.6,82.4)$ & $14.1(12.4,15.8)$ \\
\hline $65-74$ & 1622 & $12.6(10.9,14.4)$ & $72.4(69.9,74.8)$ & $24.1(21.7,26.4)$ & $63.2(60.6,65.8)$ & $79.9(77.7,82.1)$ & $21.5(19.3,23.7)$ \\
\hline \multicolumn{8}{|l|}{ Education level } \\
\hline Primary school & 3409 & $26.4(24.5,28.2)$ & $50.6(48.5,52.6)$ & $15.6(14.1,17.0)$ & $59.3(57.3,61.3)$ & $79.3(77.6,80.9)$ & $13.2(11.9,14.5)$ \\
\hline Secondary school & 2790 & $31.2(29.1,33.3)$ & $38.3(36.1,40.4)$ & $11.7(10.3,13.0)$ & $59.0(56.8,61.2)$ & $78.0(76.2,79.8)$ & $9.4(8.2,10.6)$ \\
\hline University & 1318 & $32.0(28.9,35.0)$ & $31.1(28.3,33.9)$ & $9.1(7.3,10.9)$ & $56.1(52.8,59.3)$ & $71.9(69.0,74.7)$ & $6.3(5.0,7.7)$ \\
\hline
\end{tabular}

a Values are expressed as percentages (95\% confidence interval). Hypertension: systolic blood pressure $\geq 140 \mathrm{~mm}$ Hg and/or diastolic blood pressure $\geq 90$ $\mathrm{mm} \mathrm{Hg}$ and/or use of antihypertensive medication; diabetes: fasting glucose $\geq 126 \mathrm{mg} / \mathrm{dl}$ or self-reported history of diabetes; dyslipidemia: total cholesterol $\geq 240 \mathrm{mg} / \mathrm{dl}$ and/or LDL-cholesterol $\geq 160 \mathrm{mg} / \mathrm{dl}$ and/or HDL-cholesterol $<40 \mathrm{mg} / \mathrm{dl}$ and/or triglyceride $\geq 200 \mathrm{mg} / \mathrm{dl}$ and/or use of lipid-lowering medication; overweight or obesity: body mass index $\geq 25 \mathrm{~kg} / \mathrm{m}^{2}$; history of cardiovascular disease: self-reported history of heart attack or angina or revascularization or total stroke or transient ischemic attack or heart failure.

age groups while beer consumption was more frequently reported at younger age groups.

\section{Alcohol consumption, cardiovascular risk factors and cardiovascular risk}

Compared to never smokers, current smokers showed higher rates of heavy and binge drinking in both sexes (Tables 2 and 3). Among women, light and moderate patterns of alcohol consumption were higher among non-hypertensive participants than in hypertensive ones. Also, moderate pattern was more frequent among non-diabetics than in diabetics. Among men, heavy drinking was more frequent among people with hypertension than without hypertension. Similar patterns of consumption were observed in both sexes by hypercholesterolemia condition.

Table 4 shows results of three different multiple logistic regression models depicting the association between patterns of alcohol drinking and diabetes, hypertension, dyslipidemia, increased cardiovascular risk and CVD history. Individual models were performed for each analysis and in all of them the reference category was selected to be the 'never drinkers'. The odds for hypertension condition were significantly higher for men whose alcohol consumption pattern was higher than light, whereas for women the odds were $\sim 25 \%$ lower for light and moderate alcohol consumption drinkers.
For women, the odds of having $>20 \%$ CVD risk were $\sim 40 \%$ lower than that of never drinkers for those with light and moderate consumption. The odds of having a history of CVD was $\sim 50 \%$ lower than those with a moderate consumption. For men, the odds of having $>20 \%$ CVD risk was about twice as high than in never drinkers, in those with a heavy consumption.

\section{Discussion}

\section{Main findings of this study}

Most of the cohort participants were not current drinkers and, among drinkers, moderate consumption was the most frequent pattern. Heavy and binge drinking were significantly higher among men and it is worrying that almost $14 \%$ of men reported one of those harmful patterns of alcohol consumption. Consistent with ENPRECOSP national survey in Argentina, ${ }^{23}$ wine is the most selected beverage and this is especially more significant as age increases.

This study also analyzed the relation between different patterns of alcohol consumption and different CVD risk status as diabetes, hypertension, dislipemia, $>20 \%$ CVD risk and history of CVD. Among women, an apparently protective association was found between light and moderate alcohol consumption and $>20 \%$ CVD risk and also between moderate consumption and CVD history. Although 
Table 2 Estimated prevalence and $95 \% \mathrm{Cl}$ of drinking patterns among men in the study population of the Southern Cone of Latin America in 2011-12

\begin{tabular}{|c|c|c|c|c|c|c|c|c|c|c|c|c|c|}
\hline & \multicolumn{6}{|c|}{ Patterns of alcohol drinking ${ }^{2}$} & \multicolumn{4}{|c|}{ Categories of average volume per day of drinking alcoholb } & \multicolumn{3}{|l|}{ Type of beverage } \\
\hline & Never & Former & Light & Moderate & Heavy & Binge & Abstainers & Drinker I & Drinker II & Drinker III & Wine & Beer & Spirits \\
\hline Overall & $37.2(35.8,38.5)$ & $18.3(17.2,19.3)$ & $11.8(10.9,12.7)$ & $24.2(23.0,25.4)$ & $2.9(2.5,3.3)$ & $5.6(4.9,6.3)$ & $55.5(54.1,56.9)$ & $42.6(41.2,44.0)$ & $1.2(0.9,1.5)$ & $0.7(0.5,0.9)$ & $51.7(49.6,53.8)$ & $34.7(32.6,36.8)$ & $19.7(17.9,21.5)$ \\
\hline Men & $24.4(22.6,26.2)$ & $16.8(15.2,18.3)$ & $11.5(10.1,12.8)$ & $33.5(31.5,35.4)$ & $3.9(3.2,4.6)$ & $9.9(8.6,11.3)$ & $41.2(39.2,43.3)$ & $55.6(53.6,57.7)$ & $1.8(1.3,2.4)$ & $1.3(0.8,1.8)$ & $59.1(56.4,61.8)$ & $40.6(37.9,43.4)$ & $21.4(19.1,23.7)$ \\
\hline \multicolumn{14}{|l|}{ Age groups (years) } \\
\hline $35-44$ & $27.2(23.6,30.8)$ & $13.1(10.3,15.8)$ & $12.2(9.6,14.9)$ & $32.3(28.6,36.0)$ & $2.5(1.3,3.7)$ & $12.6(9.8,15.5)$ & $40.3(36.3,44.3)$ & $57.1(53.1,61.1)$ & $1.4(0.5,2.3)$ & $1.2(0.3,2.2)$ & $52.6(47.4,57.8)$ & $51.5(46.3,56.7)$ & $22.6(18.0,27.1)$ \\
\hline $45-54$ & $23.2(20.0,26.3)$ & $16.2(13.5,19.0)$ & $11.5(9.1,13.9)$ & $34.3(30.8,37.8)$ & $3.7(2.4,5.0)$ & $11.1(8.7,13.5)$ & $39.4(35.8,43.1)$ & $57.2(53.5,60.9)$ & $2.1(1.1,3.2)$ & $1.2(0.4,2.0)$ & $58.4(53.7,63.1)$ & $40.9(36.2,45.6)$ & $22.6(18.5,26.6)$ \\
\hline $55-64$ & $20.9(18.0,23.7)$ & $20.9(18.0,23.8)$ & $11.6(9.3,14.0)$ & $34.3(31.0,37.6)$ & $5.8(4.3,7.4)$ & $6.4(4.7,8.1)$ & $41.8(38.4,45.3)$ & $54.7(51.2,58.2)$ & $2.2(1.2,3.1)$ & $1.3(0.5,2.1)$ & $64.3(59.9,68.7)$ & $29.9(25.6,34.1)$ & $18.3(14.8,21.9)$ \\
\hline $65-74$ & $24.6(21.1,28.0)$ & $22.9(19.5,26.3)$ & $8.8(6.4,11.2)$ & $33.8(30.0,37.6)$ & $5.3(3.5,7.0)$ & $4.5(2.8,6.1)$ & $47.7(43.6,51.7)$ & $48.7(44.6,52.7)$ & $1.9(0.8,3.0)$ & $1.8(0.8,2.7)$ & $75.5(70.7,80.3)$ & $20.0(15.6,24.4)$ & $19.7(15.4,24.0)$ \\
\hline \multicolumn{14}{|l|}{ Education level } \\
\hline Primary school & $22.2(19.6,24.7)$ & $17.9(15.5,20.2)$ & $11.9(9.8,14.0)$ & $31.8(29.0,34.7)$ & $5.0(3.6,6.3)$ & $11.2(8.9,13.5)$ & $40.1(37.0,43.1)$ & $56.0(52.9,59.1)$ & $2.5(1.4,3.5)$ & $1.4(0.6,2.2)$ & $57.2(53.0,61.3)$ & $38.4(34.2,42.6)$ & $13.6(10.8,16.3)$ \\
\hline Secondary school & $24.8(21.9,27.6)$ & $17.6(15.1,20.1)$ & $11.3(9.2,13.4)$ & $33.1(30.0,36.2)$ & $3.4(2.4,4.4)$ & $9.8(7.6,11.9)$ & $42.4(39.2,45.7)$ & $54.9(51.6,58.1)$ & $1.5(0.8,2.2)$ & $1.2(0.5,2.0)$ & $59.0(54.6,63.3)$ & $41.7(37.3,46.1)$ & $23.5(19.7,27.3)$ \\
\hline University & $26.9(22.6,31.1)$ & $13.7(10.6,16.8)$ & $11.3(8.2,14.4)$ & $36.2(31.8,40.7)$ & $3.2(1.9,4.5)$ & $8.5(5.8,11.3)$ & $40.7(36.0,45.3)$ & $56.5(51.8,61.2)$ & $1.5(0.6,2.5)$ & $1.3(0.3,2.3)$ & $61.9(56.0,67.8)$ & $41.9(36.0,47.9)$ & $28.4(22.9,33.9)$ \\
\hline \multicolumn{14}{|l|}{ Tobacco status } \\
\hline Never smokers & $35.1(31.7,38.5)$ & $15.7(13.1,18.2)$ & $10.1(7.8,12.4)$ & $31.2(28.1,34.4)$ & $1.7(0.8,2.5)$ & $6.2(4.4,8.0)$ & $50.8(47.3,54.4)$ & $47.7(44.2,51.3)$ & $1.0(0.4,1.6)$ & $0.4(0.1,0.7)$ & $58.3(53.4,63.3)$ & $37.2(32.4,42.0)$ & $16.9(13.2,20.6)$ \\
\hline Former smokers & $19.1(16.3,21.9)$ & $22.2(19.3,25.1)$ & $12.5(10.2,14.8)$ & $33.6(30.3,36.9)$ & $4.6(3.3,5.9)$ & $8.0(5.9,10.1)$ & $41.3(37.8,44.8)$ & 55. $9(52.4,59.4)$ & $1.7(0.8,2.5)$ & $1.1(0.5,1.7)$ & $61.0(56.4,65.5)$ & $39.5(34.8,44.2)$ & $19.6(15.8,23.4)$ \\
\hline $\begin{array}{l}\text { Current cigarettes } \\
\text { smokers }\end{array}$ & $18.2(15.3,21.1)$ & $12.8(10.4,15.2)$ & $12.0(9.6,14.5)$ & $35.7(32.1,39.3)$ & $5.5(4.0,7.0)$ & $15.8(12.8,18.7)$ & $31.0(27.6,34.4)$ & $63.7(60.1,67.3)$ & $2.8(1.7,4.0)$ & $2.5(1.2,3.7)$ & $58.2(53.7,62.7)$ & $44.2(39.6,48.8)$ & $26.3(22.1,30.4)$ \\
\hline \multicolumn{14}{|l|}{ Hypertension } \\
\hline No & $26.7(24.1,29.4)$ & $16.0(13.9,18.1)$ & $11.8(9.9,13.7)$ & $32.7(30.0,35.4)$ & $2.7(1.9,3.5)$ & $10.0(8.0,11.9)$ & $42.8(39.8,45.7)$ & $54.6(51.7,57.6)$ & $1.4(0.7,2.0)$ & $1.3(0.5,2.0)$ & $57.5(53.7,61.4)$ & $44.0(40.1,47.9)$ & $24.6(21.1,28.1)$ \\
\hline Yes & $21.5(19.1,23.8)$ & $17.7(15.5,19.9)$ & $11.1(9.2,13.0)$ & $34.4(31.7,37.2)$ & $5.3(4.1,6.5)$ & $9.9(8.0,11.8)$ & $39.2(36.4,42.1)$ & $57.0(54.1,59.8)$ & $2.4(1.6,3.2)$ & $1.4(0.8,1.9)$ & $60.9(57.2,64.7)$ & $36.7(33.0,40.4)$ & $17.7(14.7,20.6)$ \\
\hline \multicolumn{14}{|l|}{ Diabetes } \\
\hline No & $24.8(22.8,26.8)$ & $15.9(14.3,17.5)$ & $11.4(9.9,12.8)$ & $34.0(31.9,36.1)$ & $3.8(3.0,4.5)$ & $10.1(8.6,11.6)$ & $40.8(38.6,43.0)$ & $56.1(53.8,58.3)$ & $1.8(1.3,2.4)$ & $1.3(0.8,1.9)$ & $58.9(56.0,61.8)$ & $41.7(38.8,44.6)$ & $22.2(19.7,24.8)$ \\
\hline Yes & $23.1(18.3,27.9)$ & $23.5(18.8,28.1)$ & $12.2(8.3,16.2)$ & $30.0(24.8,35.2)$ & $3.4(1.6,5.2)$ & $7.7(4.3,11.2)$ & $46.6(40.9,52.3)$ & $51.0(45.4,56.7)$ & $1.4(0.3,2.5)$ & $0.9(0.1,1.8)$ & $61.9(54.0,69.8)$ & $31.3(23.5,39.1)$ & $15.0(9.5,20.6)$ \\
\hline \multicolumn{14}{|l|}{ Dyslipidemia } \\
\hline No & $23.3(20.0,26.5)$ & $16.1(13.4,18.8)$ & $9.5(7.4,11.6)$ & $35.4(31.9,38.9)$ & $4.8(3.4,6.2)$ & $10.8(8.3,13.3)$ & $39.5(35.8,43.1)$ & $56.4(52.7,60.1)$ & $2.7(1.6,3.9)$ & $1.4(0.5,2.3)$ & $62.7(58.1,67.3)$ & $41.5(36.8,46.2)$ & $18.6(14.9,22.3)$ \\
\hline Yes & $25.2(23.0,27.5)$ & $17.0(15.1,18.8)$ & $12.4(10.6,14.1)$ & $32.7(30.4,35.1)$ & $3.2(2.4,4.0)$ & $9.4(7.8,11.1)$ & $42.3(39.7,44.8)$ & $55.2(52.6,57.7)$ & $1.4(0.8,1.9)$ & $1.2(0.7,1.8)$ & $57.4(54.0,60.8)$ & $40.4(37.0,43.8)$ & $22.9(19.9,25.9)$ \\
\hline \multicolumn{14}{|l|}{ Framingham risk } \\
\hline Low & $28.3(24.8,31.9)$ & $14.0(11.3,16.8)$ & $11.9(9.4,14.3)$ & $33.1(29.5,36.7)$ & $2.3(1.2,3.4)$ & $10.3(7.8,12.8)$ & $42.4(38.6,46.3)$ & $55.5(51.6,59.4)$ & $1.5(0.6,2.4)$ & $0.6(-0.0,1.2)$ & $51.7(46.6,56.7)$ & $49.9(44.8,54.9)$ & $20.9(16.6,25.1)$ \\
\hline Med & $22.1(18.8,25.5)$ & $16.5(13.6,19.4)$ & $11.0(8.4,13.7)$ & $34.2(30.4,38.0)$ & $3.8(2.4,5.2)$ & $12.2(9.3,15.2)$ & $38.7(34.8,42.6)$ & $58.0(54.0,62.0)$ & $1.9(0.9,2.9)$ & $1.5(0.4,2.5)$ & $62.8(57.7,68.0)$ & $40.8(35.5,46.1)$ & $24.5(19.7,29.3)$ \\
\hline High & $22.1(19.2,24.9)$ & $17.6(15.1,20.2)$ & $12.8(10.4,15.3)$ & $34.4(31.2,37.7)$ & $5.4(4.0,6.8)$ & $7.5(5.6,9.4)$ & $39.8(36.5,43.1)$ & $56.9(53.5,60.3)$ & $1.8(1.0,2.7)$ & $1.5(0.8,2.2)$ & $63.6(59.2,67.9)$ & $29.9(25.7,34.0)$ & $19.8(16.2,23.3)$ \\
\hline \multicolumn{14}{|l|}{ History of CVD } \\
\hline No & $24.6(22.7,26.6)$ & $15.8(14.2,17.4)$ & $11.9(10.4,13.4)$ & $33.7(31.6,35.8)$ & $3.7(3.0,4.5)$ & $10.2(8.7,11.6)$ & $40.5(38.3,42.7)$ & $56.7(54.5,58.9)$ & $1.7(1.2,2.2)$ & $1.1(0.7,1.6)$ & $58.3(55.5,61.2)$ & $41.4(38.5,44.3)$ & $21.7(19.3,24.2)$ \\
\hline Yes & $22.5(17.9,27.2)$ & $25.0(20.2,29.8)$ & $7.9(4.7,11.2)$ & $31.4(26.2,36.5)$ & $5.0(2.7,7.3)$ & $7.9(4.3,11.4)$ & $47.8(42.2,53.4)$ & $46.3(40.7,51.9)$ & $3.1(1.2,5.0)$ & $2.8(0.3,5.3)$ & $66.6(59.0,74.2)$ & $33.5(25.6,41.4)$ & $18.0(11.8,24.1)$ \\
\hline \multicolumn{14}{|l|}{ City } \\
\hline Marcos Paz, & $38.1(34.3,41.9)$ & $10.1(7.9,12.2)$ & $0.8(0.0,1.5)$ & $41.5(37.6,45.3)$ & $1.7(0.7,2.7)$ & $8.0(5.7,10.2)$ & $48.1(44.2,52.0)$ & $51.2(47.3,55.1)$ & $0.6(0.1,1.1)$ & $0.1(-0.1,0.2)$ & $83.8(79.6,88.0)$ & $37.6(32.2,43.0)$ & $6.4(3.6,9.2)$ \\
\hline \multicolumn{14}{|c|}{ 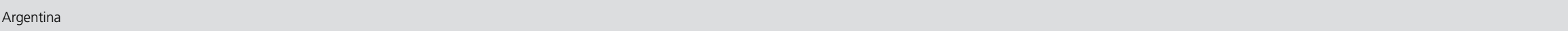 } \\
\hline $\begin{array}{l}\text { Bariloche, } \\
\text { Argentina }\end{array}$ & $21.1(18.0,24.2)$ & $13.0(10.5,15.4)$ & $18.9(15.9,21.8)$ & $33.6(30.0,37.1)$ & $7.1(5.2,8.9)$ & $6.2(4.3,8.1)$ & $34.2(30.7,37.8)$ & $61.2(57.5,64.8)$ & $3.2(1.9,4.5)$ & $1.4(0.6,2.2)$ & $52.5(48.0,57.1)$ & $31.3(26.9,35.6)$ & $5.2(3.1,7.2)$ \\
\hline
\end{tabular}


decreased risk for cardiovascular outcomes and moderate alcohol consumption has also been described for men, ${ }^{6,9}$ we did not find that association. Harmful association was observed between heavy drinking and $>20 \%$ CVD risk for men. Hypertension status was strongly associated with alcohol consumption among men with a pattern higher than light, while a protective association was observed for women that reported light and moderate levels. This last finding could be associated with the lower CVD risk observed in these levels of consumption among women.

\section{What is already known on this topic}

These observations are also in line with figure analyses done from the Euromonitor database showing that in these countries mean annual growth in sales decreased for wine and increased for beer in the last 15 years. However, $50.6 \%$ of the market share in Argentina still goes to wine and 33.2\% to beer (N. Espínola, personal communication, 18 April 2018). IHME GBD estimations for 2016 show that the DALY rates for some alcohol-attributable conditions, such as alcohol use disorders are higher for Chile than for Argentina or Uruguay. ${ }^{2}$

In relation to the observations on the association between heavy drinking and CVD risk, a meta-analysis of association of alcohol consumption with selected CVD outcomes has found that the lower risk of coronary heart disease associated with $2.5-14.9 \mathrm{~g} /$ day of alcohol consumption was stronger for women than for men. ${ }^{10}$ At the INTERHEART study, a case-control study performed in 52 different countries, a protected relationship between regular alcohol consumption and myocardial infarction ${ }^{32}$ was observed and in this case, an apparently greater protective association in women than in men was also observed. ${ }^{33}$ However, and very importantly, the protective relation with alcohol consumption was not present in the sub analysis for Latin American countries that participated in at the INTERHEART study, including wine-producing countries such as Argentina and Chile. ${ }^{34}$ As discussed in that study, different patterns of alcohol consumption or type of alcohol consumed may play a role on risk. In Chile, for example, it has been described that alcohol consumption per capita is even higher than that of some European alcoholic beverage-producing countries such as France. $^{35,36}$

Multiple published data has widely supported the association between excessive alcohol intake and the development of hypertension ${ }^{37-39}$; this is clearly correlated in our data for men. However, an apparently protective association of light and moderate consumption among women was observed with hypertension. A prospective cohort study that analyzed 


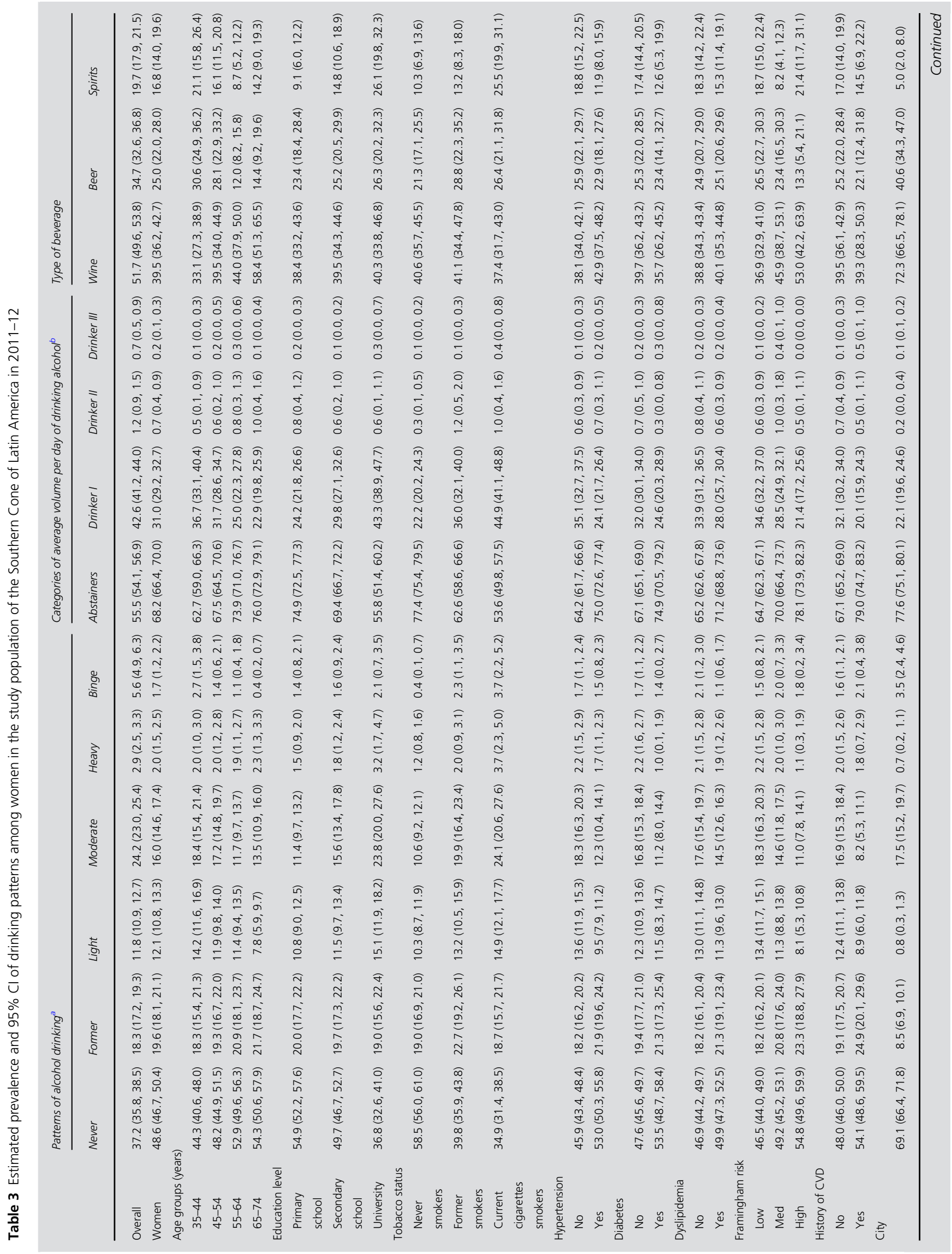


moderate alcohol consumption and risk of hypertension in $>70000$ women showed a J-shaped curve for the association. ${ }^{40}$ However, findings of studies in this field show discrepant results with no strong conclusion on prospective effect of light and moderate consumption patterns and risk of hypertension. ${ }^{37,41}$

In relation to gender differences, acute differences in moderate drinking effects have been associated with gender differences in alcohol pharmacokinetics (absorption, distribution and elimination). ${ }^{42}$ However, additional studies might shed further light on the effects of those biological differences in long-term effects by gender. In this sense, a recent systematic analysis for the Global Burden Disease Study 2016, reported that alcohol use caused far more health loss among men than women. ${ }^{43}$ Among the strengths of these results, it is important to highlight that in all performed analyses never drinkers were used as reference, which is very important as the inclusion of former drinkers in the reference group of abstainers could lead to incorrect conclusions.

\section{What this study adds}

This study provides valuable data on alcohol consumption in a population-based sample of four mid-sized cities of the Southern Cone of Latin America. To our knowledge, this is the first study that describes the association of the different patterns of alcohol consumption and cardiovascular risk on data coming from general population in this region.

\section{Limitations of this study}

Under-reporting due to alcohol stigma or 'willingness to please' could result in bias for both sexes. Self-reporting of CVD cases might not capture both ends of the severity spectrum (CVD victims and subclinical atherosclerosis). Moreover, we evaluated total stroke, but one of the complex associations of alcohol consumption and CVD is the lower relative risk observed for ischemic strokes and higher relative risk for hemorrhagic stroke type. ${ }^{10}$ Notwithstanding the fact that estimated association measures reported in the present study come from observational data, all this epidemiological knowledge comes from the first population-based cohort in the southern cone of Latin America, based on a cluster-randomized representative sampling of nearly 8000 people.

Populations net effects of alcohol on cardiovascular outcomes are significantly influenced by the type of study design used and population characteristics. There is need of an adequate, well-conducted experimental study design as a randomized clinical trial to clarify the actual effect of consumption of alcohol on cardiovascular health. General recommendations to population should thus be extremely cautious. 
Table 4 Adjusted odds ratios (ORs) and 95\% confidence intervals ( $95 \% \mathrm{Cls}$ ) for the association of cardiovascular risk with drinking patterns by gender, among study population in the Southern Cone of Latin America*

\begin{tabular}{|c|c|c|c|c|c|c|}
\hline & \multicolumn{6}{|c|}{ Adjusted ORs } \\
\hline & Never & Former & Light & Moderate & Heavy & Binge \\
\hline \multicolumn{7}{|l|}{ Men } \\
\hline Diabetes $^{a}$ & Ref & $1.30(0.89,1.91)$ & $1.31(0.80,2.15)$ & $0.91(0.64,1.30)$ & $0.80(0.40,1.60)$ & $1.01(0.56,1.81)$ \\
\hline Hypertension ${ }^{b}$ & Ref & $1.24(0.92,1.67)$ & $1.16(0.82,1.64)$ & $1.38(1.08,1.77)$ & $2.41(1.45,4.01)$ & $1.78(1.22,2.58)$ \\
\hline Dyslipidemia $^{c}$ & Ref & $1.01(0.74,1.37)$ & $1.26(0.89,1.80)$ & $0.84(0.65,1.09)$ & $0.66(0.42,1.05)$ & $0.73(0.50,1.07)$ \\
\hline$>20 \% 10$-year risk ${ }^{d}$ & Ref & $1.3(0.97,1.75)$ & $1.26(0.9,1.77)$ & $1.18(0.93,1.50)$ & $1.99(1.24,3.18)$ & $0.73(0.5,1.07)$ \\
\hline History of $C V D^{\mathrm{e}}$ & Ref & $1.24(0.85,1.80)$ & $0.73(0.42,1.28)$ & $0.89(0.63,1.25)$ & $0.88(0.48,1.62)$ & $0.90(0.50,1.65)$ \\
\hline \multicolumn{7}{|l|}{ Women } \\
\hline Diabetes $^{a}$ & Ref & $0.91(0.67,1.24)$ & $1.12(0.76,1.64)$ & $0.72(0.49,1.05)$ & $0.73(0.28,1.93)$ & $1.07(0.35,3.28)$ \\
\hline Hypertension ${ }^{\mathrm{b}}$ & Ref & $1.12(0.90,1.41)$ & $0.74(0.54,0.99)$ & $0.75(0.58,0.98)$ & $0.8(0.46,1.40)$ & $1.54(0.78,3.05)$ \\
\hline Dyslipidemiac $^{c}$ & Ref & $1.11(0.89,1.39)$ & $0.95(0.73,1.24)$ & $0.86(0.68,1.08)$ & $1.07(0.65,1.74)$ & $0.53(0.28,1.01)$ \\
\hline$>20 \% 10$-year risk ${ }^{d}$ & Ref & $1.03(0.76,1.4)$ & $0.58(0.38,0.88)$ & $0.62(0.43,0.88)$ & $0.56(0.26,1.24)$ & $1.05(0.38,2.92)$ \\
\hline History of $C V D^{e}$ & Ref & $1.03(0.75,1.41)$ & $0.73(0.48,1.11)$ & $0.48(0.30,0.76)$ & $1.05(0.51,2.16)$ & $1.49(0.56,3.97)$ \\
\hline
\end{tabular}

${ }^{a}$ Compared to non-diabetics. Adjusted by age, sex, education, city, current smoking, overweight or obesity, hypertension and dyslipidemia.

${ }^{b}$ Compared to non-hypertensives. Adjusted by age, sex, education, city, current smoking, overweight or obesity, diabetes and dyslipidemia.

${ }^{c}$ Compared to normolipemics. Adjusted by age, sex, education, city, current smoking, overweight or obesity, hypertension and diabetes.

${ }^{d}$ Compared to $\leq 20 \% 10$-year risk. Adjusted by age, sex, education and city.

${ }^{e}$ Compared to no CVD history participants. Adjusted by age, sex, education, city, current smoking, overweight or obesity, diabetes, hypertension, dyslipidemia.

*Bold indicates statistical significance.

\section{Conclusions}

In this representative population-based sample of the Southern Cone of Latin America, the majority of the participants reported to be current non-drinkers and, among drinkers, moderate alcohol consumption was the most frequent pattern observed.

For women, the odds of having $>20 \%$ CVD risk were lower for those with light and moderate consumption than that of never drinkers. For history of CVD, the odds were also lower in those with a moderate consumption. For men, the odds of having $>20 \%$ CVD risk were about twice as high among those with a heavy consumption than in never drinkers.

\section{Supplementary data}

Supplementary data are available at the Journal of Public Health online.

\section{Acknowledgments}

The authors would like to gratefully acknowledge the contributions of our librarian, Daniel Comandé, regarding the electronic searches.

\section{Funding}

This work was supported by the National Heart, Lung, and Blood Institute (NHLBI) grant number HHSN26820090 0029C

\section{References}

1 Informe sobre la situación mundial de las enfermedades no transmisibles. World Health Organization, 2014. http://apps.who.int/iris/ bitstream/10665/149296/1/WHO_NMH_NVI_15.1_spa.pdf (22 January 2018, date last accessed).

2 GHDx. Global Health Data Exchange http://ghdx.healthdata.org/ gbd-results-tool (17 January 2018, date last accessed).

3 Di Castelnuovo A, Costanzo S, Bagnardi V. Alcohol dosing and total mortality in men and women: an updated meta-analysis of 34 prospective studies. Arch Intern Med 2006;166(22):2437-45.

4 Argentinean National Study in population from 12 to 65 years old, on Consumption of Psychoactive Substances, SEDRONAR, 2018: http://www.observatorio.gov.ar/media/k2/attachments/2017-1005ZEncuestaZHogaresZconZcuestionario.pdf (1 May 2018, date last accessed).

5 Corrao G, Bagnardi V, Zambon A et al. A meta-analysis of alcohol consumption and the risk of 15 diseases. Prev Med 2004;38(5): 613-9. 
6 Camargo CA Jr, Stampfer MJ, Glynn RJ et al. Moderate alcohol consumption and risk for angina pectoris or myocardial infarction in U.S. male physicians. Ann Intern Med 1997;126(5):372-5.

7 Gronbaek M, Becker U, Johansen D et al. Type of alcohol consumed and mortality from all causes, coronary heart disease, and cancer. Ann Intern Med 2000;133(6):411-9.

8 Gemes K, Janszky I, Laugsand LE et al. Alcohol consumption is associated with a lower incidence of acute myocardial infarction: results from a large prospective population-based study in Norway. J Intern Med 2016;279(4):365-75.

9 Corrao G, Rubbiati L, Bagnardi V et al. Alcohol and coronary heart disease: a meta-analysis. Addiction 2000;95(10):1505-23.

10 Ronksley PE, Brien SE, Turner BJ et al. Association of alcohol consumption with selected cardiovascular disease outcomes: a systematic review and meta-analysis. BMJ 2011;342:d671.

11 Xi B, Veeranki SP, Zhao M et al. Relationship of alcohol consumption to all-cause, cardiovascular, and cancer-related mortality in U.S. adults. J Am Coll Cardiol 2017;70(8):913-22.

12 Roerecke M, Rehm J. The cardioprotective association of average alcohol consumption and ischaemic heart disease: a systematic review and meta-analysis. Addiction 2012;107(7):1246-60.

13 Roerecke M, Rehm J. Ischemic heart disease mortality and morbidity rates in former drinkers: a meta-analysis. Am J Epidemiol 2011; 173(3):245-58.

14 Taylor B, Irving HM, Baliunas D et al. Alcohol and hypertension: gender differences in dose-response relationships determined through systematic review and meta-analysis. Addiction 2009;104(12):1981-90.

15 Samokhvalov A, Irving H, Rehm J. Alcohol as a risk factor for atrial fibrillation: a systematic review and meta-analysis. Eur J Cardiovasc Prev Rehabil 2010;17(6):706-12.

16 Patra J, Taylor B, Irving $\mathrm{H}$ et al. Alcohol consumption and the risk of morbidity and mortality for different stroke types - a systematic review and meta-analysis. BMC Public Health 2010;10:258-8.

17 Bardach AE, Caporale JE, Rubinstein AL et al. Impact of level and patterns of alcohol drinking on coronary heart disease and stroke burden in Argentina. PLoS One 2017;12(3):e0173704.

18 Hernandez-Hernandez A, Gea A, Ruiz-Canela M et al. Mediterranean alcohol-drinking pattern and the incidence of cardiovascular disease and cardiovascular mortality: the SUN project. Nutrients 2015;7(11): 9116-26.

19 Bobak M, Malyutina S, Horvat P et al. Alcohol, drinking pattern and all-cause, cardiovascular and alcohol-related mortality in Eastern Europe. Eur J Epidemiol 2016;31(1):21-30.

20 Haheim LL, Olsen I, Ronningen KS. Oral infection, regular alcohol drinking pattern, and myocardial infarction. Med Hypotheses 2012;79 (6):725-30

21 WHO. Library Cataloguing-in-Publication Data. Global status report on alcohol and health, 2014 .http://www.who.int/substance abuse/publications/global_alcohol_report/en/ (2 May 2015, date last accessed).

$222^{\text {a }}$ Encuesta Nacional de Factores de Riesgo de Enfermedades No Transmisibles, 2013. http://www.msp.gub.uy/sites/default/files/
archivos_adjuntos/2DA_ENCUESTA_NACIONAL_final2_digital. pdf (22 January 2018, date last accessed).

23 ENPreCoSP. Encuesta Nacional sobre Prevalencias de Consumo de Sustancias Psicoactivas, 2011. http:/ /www.indec.gob.ar/nivel4_default. asp?id_tema_1=4\&id_tema_2=32\&id_tema_3=67 (22 January 2018, date last accessed).

24 Rubinstein AL, Irazola VE, Poggio R et al. Detection and follow-up of cardiovascular disease and risk factors in the Southern Cone of Latin America: the CESCAS I study. BMJ Open 2011;1(1):e000126.

25 Rubinstein AL, Irazola VE, Calandrelli M et al. Multiple cardiometabolic risk factors in the Southern Cone of Latin America: a population-based study in Argentina, Chile, and Uruguay. Int J Cardiol 2015;183C:82-8.

26 Cuidados innovadores para las condiciones crónicas: Organización y prestación de atención de alta calidad a las enfermedades crónicas no transmisibles en las Américas, 2013. http://www.paho.org/hq/index. php?option $=$ com_docman\&task $=$ doc_view\&gid $=22257+\&$ Itemid $=$ 999999\&lang=es (10 March 2016, date last accessed).

27 Friedewald WT, Levy RI, Fredrickson DS. Estimation of the concentration of low-density lipoprotein cholesterol in plasma, without use of the preparative ultracentrifuge. Clin Chem 1972;18(6):499-502.

28 D'Agostino RB Sr, Vasan RS, Pencina MJ et al. General cardiovascular risk profile for use in primary care: the Framingham Heart Study. Circulation 2008;117(6):743-53.

29 Drinking Levels Defined. National Institute on Alcohol Abuse and Alcoholism. https://www.niaaa.nih.gov/alcohol-health/overviewalcohol-consumption/moderate-binge-drinking (22 January 2018, date last accessed).

30 Rehm J, Room R, Monteiro M et al. Alcohol Use. In: Ezzati M, Lopez AD, Rodgers A, et al. Comparative Quantification of Health Risks. Geneva 2004;959-1108.

31 Levy P, Lemeshow S. Sampling of Populations: Methods and Applications, 4th edn. United States: John Wiley \& Sons, 2013.

32 Yusuf S, Hawken S, Ounpuu S et al. Effect of potentially modifiable risk factors associated with myocardial infarction in 52 countries (the INTERHEART study): case-control study. L ancet 2004;364(9438):937-52.

33 Leong DP, Smyth A, Teo KK et al. Patterns of alcohol consumption and myocardial infarction risk: observations from 52 countries in the INTERHEART case-control study. Circulation 2014;130(5):390-8.

34 Lanas F, Avezum A, Bautista LE et al. Risk factors for acute myocardial infarction in Latin America: the INTERHEART Latin American study. Circulation 2007;115(9):1067-74.

35 Encuesta Nacional de Salud de Chile, 2017. http://www.ipsuss. cl/ipsuss/site/artic/20171122/asocfile/20171122142253/ens_ 2016_17_primeros_resultados.pdf (20 January 2018, date last accessed).

36 Margozzini P, Sapag J El consumo riesgoso de alcohol en Chile: Tareas pendientes y oportunidades para las políticas públicas 2015. http:/ / politicaspublicas.uc.cl/wp-content/uploads/2015/03/N\% C2\%B0-75-El-consumo-riesgoso-de-alcohol-en-Chile.pdf.

37 Pareek M, Olsen MH. Alcohol and blood pressure. Lancet 2017;2 (2):e63-4. 
38 Klatsky AL, Friedman GD, Siegelaub AB et al. Alcohol consumption and blood pressure. Kaiser-Permanente Multiphasic Health Examination data. N Engl J Med 1977;296(21):1194-1200.

39 Fuchs FD, Chambless LE, Whelton PK et al. Alcohol consumption and the incidence of hypertension: the atherosclerosis risk in communities study. Hypertension 2001;37(5):1242-50.

40 Thadhani R, Camargo CA Jr., Stampfer MJ et al. Prospective study of moderate alcohol consumption and risk of hypertension in young women. Arch Intern Med 2002;162(5):569-74.
41 Djousse L, Mukamal KJ. Alcohol consumption and risk of hypertension: does the type of beverage or drinking pattern matter? Rev Esp Cardiol 2009;62(6):603-5.

42 Mumenthaler MS, Taylor JL, O'Hara R et al. Gender differences in moderate drinking effects. Alcohol Res Health 1999;23(1):55-64.

43 Collaborators GBDA. Alcohol use and burden for 195 countries and territories, 1990-2016: a systematic analysis for the Global Burden of Disease Study 2016. Lancet 2018;392(10152): 1015-35. 